\title{
Electrochemical Behavior of Co-Cr Alloy in Hygienic Tablets Solution
}

\author{
Denise Pupim ${ }^{a}$, Raniel Fernandes Peixoto ${ }^{b}$ (1), Ana Paula Macedo ${ }^{a}$ (D), \\ Maria da Gloria Chiarello de Mattos ${ }^{a}$, Rodrigo Galo * (1)
${ }^{a}$ Universidade de São Paulo, Faculdade de Odontologia de Ribeirão Preto, Departamento de Materiais Dentários e Prótese, Avenida do Café, Monte Alegre, 14040-904, Ribeirão Preto, SP, Brasil.
${ }^{b}$ Universidade Federal do Ceará, Faculdade de Farmácia, Odontologia e Enfermagem, Departamento de Odontologia Restauradora, Rua Monsenhor Furtado, Rodolfo Teófilo, 60430-350, \\ Fortaleza, CE, Brasil.
}

Received: July 08, 2021; Revised: October 19, 2021; Accepted: December 01, 2021

\begin{abstract}
Objective: The aim of this study was to evaluate the electrochemical behavior of a cobalt-chromium (Co-Cr) dental alloy after immersion in denture cleansers. Method: Twenty-four specimens (Ø13×2mm) of $\mathrm{Co}-\mathrm{Cr}$ were produced and divided into three groups $(\mathrm{n}=8)$ according to their experimental condition. The group 1 (control group) was composed only of distilled water, group 2 received a hygienic tablet $\left(\right.$ Corega $\mathrm{Tabs}^{\mathrm{TM}}$ ) at the moment that electrochemical test started, while the group 3 received the hygienic tablet (Corega Tabs $\left.{ }^{\mathrm{TM}}\right) 1 \mathrm{~h}$ after immersion. The electrochemical tests recorded the open circuit potential $(\mathrm{OCP})$ and current density $\left(\mathrm{i}_{\text {corr }}\right)$. The surfaces of specimens were examined using a SEM. Data were statistically analyzed using analysis of variance (ANOVA) and Duncan test' multiple comparisons post hoc analysis $(\alpha=0.05)$. Results: The values of OCP and $i_{\text {corr }}$ revealed statistically differences between the groups. The highest results were recorded for group $2(-26.87 \pm 48.48 \mathrm{mV} ; 0.29 \pm 0.22 \mu \mathrm{A})$, which were similar to group $3(-47.37 \pm 35.36 \mathrm{mV} ; 0.26 \pm 0.10 \mu \mathrm{A})$, and these values were difference to group 1 $(-314.87 \pm 24.22 \mathrm{mV} ; 0.50 \pm 0.17 \mu \mathrm{A})$. SEM image show high corrosion with Corega Tabs ${ }^{\mathrm{TM}}$. Conclusion: The immersion in denture cleanser solution was not detrimental to the Co-Cr dental alloy and presented a lower tendency to corrosion process development than the control group.
\end{abstract}

Keywords: corrosion; dental alloy; hygienic tablet; $\mathrm{Co}-\mathrm{Cr}$ alloy.

\section{Introduction}

Dental alloys are a critical point to achieve greater longevity and success of the prosthetic treatment, the maintenance of patient's oral healthy and quality of life. When the patient receives the prosthesis, an important step of the treatment begins: the prosthetic care ${ }^{1}$. The patient must be informed about periodic returns to maintain the oral health, the prosthetic cleaning and the usual habits that will contribute to prevent problems such as mucosal lesions s,3. $^{2,3}$. Some agents are used for denture cleansers, classified as mechanical and chemical agents ${ }^{4,5}$.

The chemical cleaning consists of immersing the prosthesis in solution with detergent, solvent or antimicrobial agents, and these solutions can be employed individually or associated with brushing ${ }^{6}$. However, the majority of elderly patients for presenting advanced senility or debilitating diseases cannot effectively brush their dentures ${ }^{7}$. The use of chemical cleaners associated with the mechanical method of cleaning could be an alternative for solving the problem of these patients with the cleaning of the dentures ${ }^{8}$. Moreover, the immersion of denture in some solution has been indicated ${ }^{8}$, because a great biofilm accumulation is the main etiological factor of stomatitis by Candida spp, where the attachment areas from the prosthesis are a potential reservoir of Candida albicans ${ }^{1,9}$.

*e-mail: rogalo@forp.usp.br
Add to it, the biofilm control only through brushing seems not to be as effective as cleansers for use in plaque reduction and preventing stomatitis associated with C. albicans ${ }^{10}$. The combination of mechanical and chemical methods seems to be the best choice for an effective cleaning.

The cleaners indicated to clean the removable partial dentures are important to maintain the oral mucosa cleaned and healthy, once the biofilm can act as an adjuvant on the stomatitis development ${ }^{11}$, as well as other local manifestations that can lead to systemic problems ${ }^{12-15}$. There are several cleansers available to cleaning and conserve the dentures. Immersion denture cleansers could be divided into five groups: alkaline peroxides, alkaline hypochlorite, diluted acids, disinfecting agents and enzymes ${ }^{11}$. However, the main problem rely on the majority of users have never received enough information regarding the correct way to clean the dentures with each product, often using homemade products which can lead to deterioration and tarnish of metal-frameworks ${ }^{1}$. Chlorine is reported by Keyf et al. ${ }^{16}$, as a product related to tarnishing and corrosion of $\mathrm{Co}-\mathrm{Cr}$ frameworks and bleaching of acrylic $\operatorname{resin}^{10}$. The alkaline peroxides are presented in powder or tablet form that when in contact with water, became a hydrogen peroxide solution ${ }^{17-18}$. Relative to peroxide, it have been related to injury on the materials used in dentures, especially in the metal components of the prosthesis devices as surface 
oxidation and ions release in the solution ${ }^{11}$. Furthermore, it has been reported that immersion in the alkaline peroxides are useful in cleaning the prostheses, but the mechanical action cannot be overlooked.

Even with excellent biomechanical properties ${ }^{18-20}$, biocompatibility ${ }^{12,21}$, high fracture toughness, corrosion and wear resistance ${ }^{19,22-25}$ alloys can undergo due several factors. Among these factors, changes in $\mathrm{pH}$ of the oral media due the diet and food decomposition contributing to alloy degradation ${ }^{25,26-28}$, the use of fluorated products as toothpastes and mouthwashes that are usually indicated to the prosthetic cleaning ${ }^{11,29-31}$, range of temperature and mechanical action of wear caused by the contact between tooth and metal ${ }^{18,20,27}$. The corrosion and wear of alloys may cause adverse effects such as metallic taste, oral burning, sensitivity, and allergic reactions due metallic ions release to oral and systemic media as corrosion products ${ }^{12,19,26,32}$. The corrosion behavior of metallic materials is the main property to be analyzed on the manufacturing of prosthetic frameworks due biocompatibility and cytotoxicity of the products from corrosion process ${ }^{24,33-34}$.

The electrochemical tests are important in dentistry due corrosion reactions that occurs in the environment, which the prosthesis is inserted, a cleaning media or an oral media during its function. Thus, the aim of the present study was to analyze the electrochemical behavior of a cobalt-chromium alloy used in manufacturing of removable partial denture frameworks, immersed on a solution containing hygienic tablets of alkaline peroxide and enzyme (Corega Tabs ${ }^{\mathrm{TM}}$, Stanfford-Miller Ind. Rio de Janeiro, RJ, Brazil), simulating different situations of contact between alloy and solution. The hypothesis was that immersion in denture cleansers would have an effect on the corrosion resistance of $\mathrm{Co}-\mathrm{Cr}$ dental alloys.

\section{Materials and Methods}

\subsection{Specimens preparation}

The chemical composition of Co-Cr dental alloys specimens (Co-61\%; Cr-24\%; W-8\%; Mo-2,5\%; Nb-1\%; Mn-1\%; Si-1\%; e, Fe-1\%, DFS, Ländenstrabe, Riedenburg, Germany) measuring $13 \mathrm{~mm}$ diameter x $2 \mathrm{~mm}$ thick were prepared using the conventional flame cast technique and injection by centrifugation.

The specimens were polished with abrasive paper up to grit 2000 mesh size and followed by polishing stages with $3-\mu \mathrm{m}$ and $1-\mu \mathrm{m}$ grit diamond suspension (Struers, Glasgow, UK). After polishing, the specimens were ultrasonic cleaned in an ultrasonic vat containing alcohol for 15 minutes followed by 10 minutes in distilled water to remove residual polish products. The samples were dried and assembled in electrochemical cells to initiate testing.
The specimens were divided into three groups $(n=8)$. The distribution of samples is specified in Table 1. The control group (group 1) had only distilled water without the addition of hygienic product. In the other groups were used distilled water and added hygienic tablets Corega Tabs ${ }^{\mathrm{TM}}$ (sodium bicarbonate, citric acid, sodium carbonate, potassium per sulfate, sodium perborate, sodium benzoate, polyethylene glycol 8000, Laurel sulfoacetate, sodium vinyl acetate copolymer, sodium stearate, menthol, flavorings, and dyes) to start the electrochemical test (group 2) and after 1 hour of start the electrochemical test (group 3).

\subsection{Corrosion test}

The corrosion test (electrochemical behavior) was performed using a Potentiostat (PGP201 Radiometer Analytical, Copenhagen, Denmark) controlled by Voltamaster-4 software (Voltamaster, Radiometer Analytical, Copenhagen, Denmark). The measurements were made against a standard calomel electrode (SCE/B20B110 - Radiometer Analytical, Copenhagen, Denmark) and a platinum plate used as a counter electrode (wire B35M110 - Radiometer Analytical, Copenhagen, Denmark) and the area of alloy in contact with the electrolyte was $3.64 \mathrm{~cm}^{2}$ of the alloy used as the working electrode.

Potentiodynamic polarization tests were performed after an initial delay time at equilibrium state of 1 hour in order to stabilize the surface at open circuit potential (OCP) for group 1 and 2 . In group 3, the potentiodynamic polarization test started 2 hours later because the effervescent tablet was added 1 hour after the start of the open circuit potential (OCP). These tests were carried out in the anodic direction starting at $-0.5 \mathrm{~V}$ up to $2.0 \mathrm{~V}$, with a scan rate of $2 \mathrm{mV} / \mathrm{s}$. Values of open circuit potential (OCP), passivation current density $\left(\mathrm{i}_{\text {pass }}\right)$ and current density $\left(\mathrm{i}_{\text {corr }}\right)$ were recorded; the OCP values were evaluated for one hour and the potentiodynamic polarization curves analyzed.

The surfaces of specimens were examined using a scanning electron microscope (EVO 10; CARL ZEISS, Jena, Germany). The samples were properly stored in closed containers until the tests were conducted and then, the specimens were examined at $\times 200$ and $\times 1000$ magnifications under high vacuum.

\subsection{Statistical analysis}

Data were analyzed using one-way analysis of variance (ANOVA) and post-hoc Duncan's test to assess the effect of hygienic tablets on the Co-Cr dental alloy. The Statistical Package for the social Sciences (version 17.0; SPSS Inc., Chicago, IL, USA) was used for the statistical analysis. For all tests, a 5\% level of significance was adopted.

Table 1. Experimental groups, solutions and time used in the study.

\begin{tabular}{ccc}
\hline Group & Solution & Time \\
\hline Group 1 & $100 \mathrm{ml}$ distilled water (Control group) & Contact during whole electrochemical test \\
\hline Group 2 & $100 \mathrm{ml}$ distilled water +1 Corega Tabs $®$ tablet & Contact during whole electrochemical test \\
\hline Group 3 & $100 \mathrm{ml}$ distilled water +1 Corega Tabs $®$ tablet & Tablet added $1 \mathrm{~h}$ after the electrochemical test starts \\
\hline
\end{tabular}




\section{Results}

Table 2 shows the values obtained in the electrochemical test and the standard deviations for each group, presenting the open circuit potential (OCP) and current density $\left(\mathrm{i}_{\text {corr }}\right)$ The highest OCP and $i_{\text {corr }}$ values were recorded in group 2 , which were similar to group 3 and different to the group 1 . The results showed that tests in cleansers solutions resulted in significant differences between the OCP values indicating similar tendency to corrosion for the cleansers solutions and difference trend to control group (group 1). In addition, specimens tested in the cleanser's solutions exhibited very similar $i_{\text {corr }}$ values and differences to the group 1 . The highest values of current density of passivation $\left(i_{\text {pass }}\right)$, were recorded for the control group, while group 2 and 3 and G2 were statistically similar. Then, it can be stated that cleansers solutions alter the polarization behavior of $\mathrm{Co}-\mathrm{Cr}$ dental alloys, significantly.

Figure 1 shows the polarization curves of $\mathrm{Co}-\mathrm{Cr}$ according to the solution, where the behavior of group 2 and 3 were similar, and it was noticed in the curves different domains that can be observed in the tested solutions. The cathodic areas in the potential nearby $-400 \mathrm{mV}$. A passivation plateau was found between the values around $300 \mathrm{mV}$ and around $600 \mathrm{mV}$ and a transpassive area was observed for all conditions above values around $600 \mathrm{mV}$ due to transpassive oxidation.

Before the potentiodynamic polarization tests, no attack was identified on any specimen and all specimens showed homogeneous microstructure (Figure 2a). After the test, the specimens demonstrated the atypical dendritic microstructures obtained for the $\mathrm{Co}-\mathrm{Cr}$ alloy and the microstructure exhibited two distinct regions (Figure 2c, d), with dissolution of the dental alloys and pits were seen on most specimens and demonstrated high corrosion in contact with Corega $\mathrm{Tabs}^{\mathrm{TM}}$, except in the group in contact with distilled water (Control Group).

\section{Discussion}

Several studies have investigated the effect of denture cleansers on the physical and mechanical properties of denture base resins ${ }^{35-36}$. However, there are very few studies that used the removable partial denture frameworks manufactured with cobalt-chromium dental alloys in immersion of alkaline peroxides products ${ }^{9}$. Based on the results of the present study, the hypothesis was accepted. The immersion in denture cleanser of the alkaline peroxides influenced the corrosion resistance of the $\mathrm{Co}-\mathrm{Cr}$ dental alloys.

Life expectancy has increased as well as the need for prosthesis to elderly population. The biofilm control and proper hygiene are important factors that should be prioritized, especially when few teeth remaining and they become prosthetic abutments ${ }^{9,37}$. According to Barreiro et al. ${ }^{1}$, oral care must include instructions regarding oral health to reduce the plaque index and control periodontal disease, avoiding caries and other oral health problems on the remaining teeth. The authors also noted that in general, patients did not receive adequate information about the right denture care, causing functional and social problems and the inadequate use of cleansers can damage the metallic frameworks, may causing tarnish and corrosion, decreasing the durability of the prosthetic devices ${ }^{1}$. According to Correa et al. ${ }^{15}$, fluoride can increase the corrosion and surface roughness, providing the adherence of microorganisms on the alloy surface. It is known that the corrosion resistance of a metal or alloy is dependent not only their behavior, but also extensive interactions that occur with the medium in which the material is inserted ${ }^{25}$.

The present study showed that the potentiodynamic measurements were carried out in order to determine the local corrosion, which is associated with the breakdown of passive layer. The results of the electrochemical test exhibited that, in general, in the first minutes of action, the effervescence of hygienic tablet seems produced an immediate action, with effective cleaning, stabilizing the media and decreasing the corrosion rate, which was confirmed by lowest OCP values. It is suggested that the media provide a thin film on the alloy surface during of immersion. However, over time, changes in dynamic polarization curves were observed and the current density $\left(\mathrm{i}_{\text {corr }}\right)$ values showed an increase to corrosion.

Therefore, it could be hypothesized that lowest values of OCP were recorded during specific period, featuring low tendency to corrosion matching with the immersion time suggested by the manufacturer ( 5 minutes). However, after the effervescence of the tablet, the potentiodynamic test had been started, recording higher values of $\mathrm{i}_{\text {corr }}$, demonstrating a greater tendency to corrosion provided by the environment. It has been observed that such corrosion occurred by prolonged

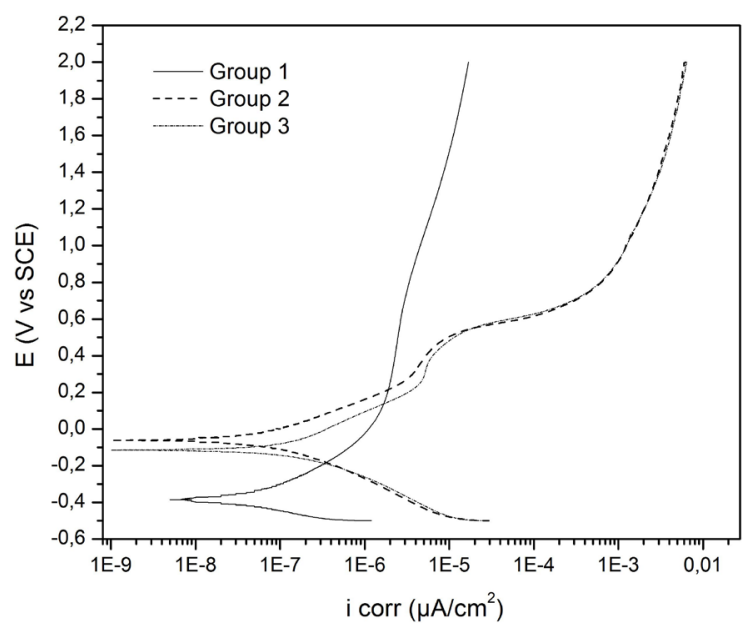

Figure 1. Potentiodynamic polarization curves of $\mathrm{Co}-\mathrm{Cr}$ alloy for each group.

Table 2. Mean and standard deviation of $\mathrm{E}_{o c p}, \mathrm{i}_{c o r r}$ and $\mathrm{i}_{\text {pass }}$ as a function of corrosion process in the different groups.

\begin{tabular}{cccc}
\hline Solution & $\mathrm{E}_{\text {ocp }}(\mathrm{mV})$ & $\mathrm{i}_{\text {corr }}\left(\mu \mathrm{A} / \mathrm{cm}^{2}\right)$ & $\mathrm{i}_{\text {pass }}\left(\mu \mathrm{A} / \mathrm{cm}^{2}\right)$ \\
\hline Group 1 & $-314.87 \pm 24.22^{\mathrm{A}}$ & $0.050 \pm 0.017^{\mathrm{A}}$ & $1.2348 \pm 0.7729^{\mathrm{A}}$ \\
\hline Group 2 & $-26.87 \pm 48.28^{\mathrm{B}}$ & $0.295 \pm 0.220^{\mathrm{B}}$ & $0.0002 \pm 0.0002^{\mathrm{B}}$ \\
\hline Group 3 & $-47.37 \pm 35.36^{\mathrm{B}}$ & $0.266 \pm 0.106^{\mathrm{B}}$ & $0.0001 \pm 0.00004^{\mathrm{B}}$ \\
\hline
\end{tabular}

Uppercase letters indicate a statistically significant difference within the row. 
(a) Without corrosion

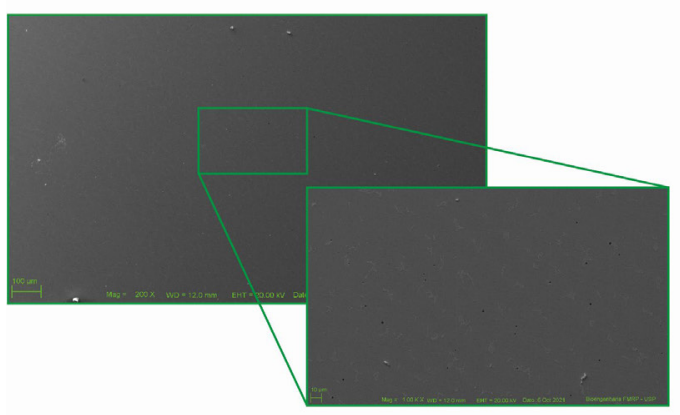

(c) Group 2

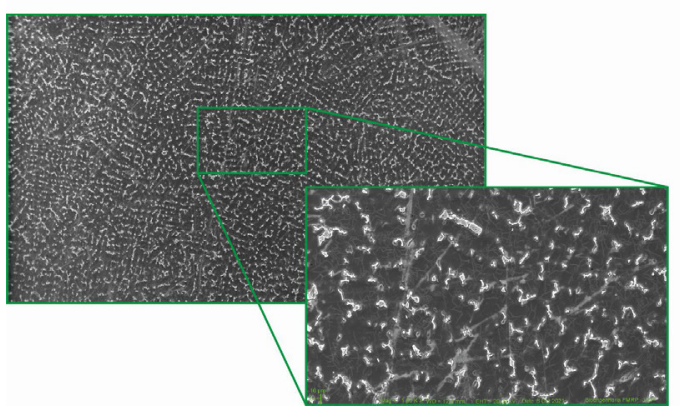

(b) Group 1

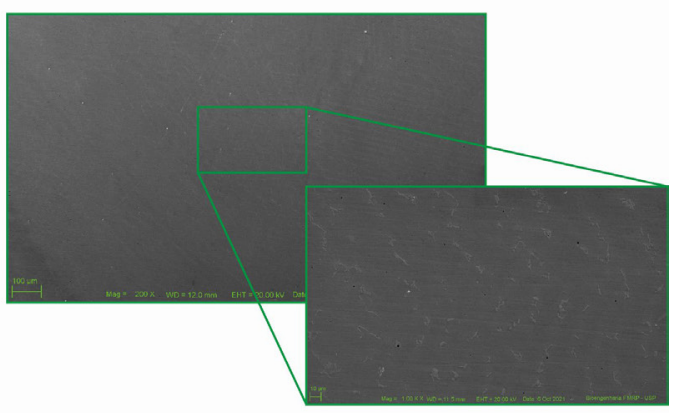

(d) Group 3

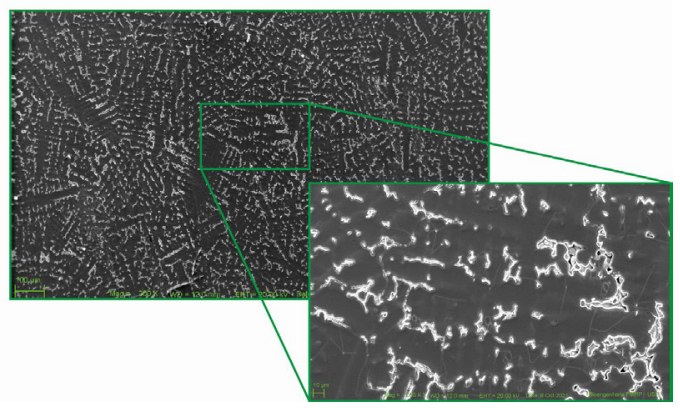

Figure 2. SEM images of the Co-Cr dental alloy for each group (Magnification $\times 200$ and $\times 1,000$ ): a) Co-Cr dental alloy without corrosion test; b) Group 1- distilled water (Control group); c) Group 2: distilled water + Corega Tabs ${ }^{\text {TM }}$ tablet; and Group 3: distilled water + 1hour Corega Tabs ${ }^{\mathrm{TM}}$ tablet, respectively.

period of immersion of the solution on the metal, because when effervescent tablets are in contact with water, the decomposition of sodium perborate occurs, producing an alkaline peroxide solution. This solution release oxygen, which promotes mechanical cleaning through the bubbles released and the tendency to corrosion observed in this study increased after time recommended by the manufacturer may result in oxygen ions released from the hygienic tablet ${ }^{9}$. However, Felipucci et al. ${ }^{11}$, suggested that the instruction for use should be reformulated as well as with recommendation for brushing after immersion, for promoting complete removal of the alkaline peroxides.

On the other hand, Davi et al. ${ }^{9}$, found that the alloy immersion in disinfectant solutions can influenced the release of metal ions and exhibited a significant increase in surface roughness of resin, although did not affect the roughness of the metal. Moreover, other author conducted a similar study to evaluate the effect of different cleansers in surface roughness changes of alloys suitable for the fabrication of removable partial dentures, using different effervescent tablets and mouthwashes and they results showed that although the values of surface roughness have increased after using the products, the results were not statistically significant ${ }^{11}$. However, tarnish was found and suggests that corrosion occurred, reporting that the use of sodium hypochlorite at $0.05 \%$ and citric acid tablets can cause harmful effects to metal components of the removable partial dentures.

The SEM analysis (Fig. 2) showed that the corrosion process initially occurs on the surface. Pits may be the result of the dissolution of the precipitates of the cleaning solutions or, respectively, their detachment due to the dissolution. The Co-Cr surface itself did not show any evidence of significant corrosion. The dental alloys when submitted to cleaning solutions presented a more severely corroded surface, with the formation of a typical surface morphology of a uniform corrosion with the dissolution of the corrosion products. Visually, the surface was blackened.

Although the tablet manufacturer has indicated its use in metallic structures, this tablet caused surface corrosion of the evaluated metal alloys. It was observed that such corrosion occurred by prolonged deposition of the solution on the metal. Therefore, the results obtained in this study suggest that the instructions for use should be reformulated not only with rinsing in running water, but also with the recommendation of brushing after immersion, to promote total removal of the product and ensure a prolonged service life of the dentures ${ }^{9-11}$.

The present study has some methodological limitations; only one type of dental alloy was evaluated and the oral conditions, such as biofilm, temperature and $\mathrm{pH}$, were not considered, which would have some influence on the action of denture cleansers.

\section{Conclusion}

Under the conditions of the present study, it could be concluded that the use of hygienic tablets containing alkaline peroxide and enzyme combined with distilled water gave 
similar corrosive effect on the Co-Cr specimens immersed immediately and one hour after the placement on the cleaner solution.

\section{References}

1. Barreiro DM, Scheid PA, May LG, Unfer B, Braun KO. Evaluation of procedures employed for the maintenance of removable dentures in eldery individuals. Oral Health Prev Dent. 2009;7(3):243-9.

2. Nogués L, Martinez-Gomis J, Molina C, Peraire M, Salsench $\mathrm{J}$, Sevilla P, et al. Dental casting alloys behavior during power toothbrushing with toothpastes with various abrasivities. Part I: wear behavior. J Mater Sci Mater Med. 2008;19(9):3041-8.

3. Parizi MTT, Taheri S, Amini P, Afshar MK, Afshar MK. Evaluation of denture hygiene among removable denture wearers referred to clinics of Kerman, Iran. J Oral Health Oral Epidemiol. 2013;2(1):44-8.

4. Souza ME, Lima L, Lima CR, Zavaglia CA, Freire CM. Effects of $\mathrm{pH}$ on the electrochemical behaviour of titanium alloys for implant applications. J Mater Sci Mater Med. 2009;20(2):54952.

5. Cinquanta L, Varoni EM, Barbieri C, Sardella A. Patient attitude and habits regarding removable denture home hygiene and correlation with prosthesis cleanliness: a cross-sectional study of elderly Italians. J Prosthet Dent. 2021;125(5):772.e1-7.

6. Andrade IM, Cruz PC, Silva CH, Souza RF, Hde FP, Candido $\mathrm{RC}$, et al. Effervescent tablets and ultrasonic devices against Candida and mutans streptococci in denture biofilm. Gerodontology. 2011;28(4):264-70.

7. Peracini A, Davi LR, Ribeiro NQ, Souza RF, Lovato-Silva $\mathrm{CH}$, Paranhos HFO. Effect of denture cleansers on physical properties of heat-polymerized acrylic resin. J Prosthodont Res. 2010;54(2):78-83.

8. Barnabé W, Neto TM, Pimenta FC, Pegoraro LF, Scolaro JM. Efficacy of sodium hypochlorite and coconut soap used as disinfecting agents in the reduction of denture stomatitis, Streptococcus mutans and Candida albicans. J Oral Rehabil. 2004;31(5):453-9.

9. Davi LR, Felipucci DNB, Souza RF, Bezzon OL, Lovato-Silva $\mathrm{CH}$, Pagnano VO, et al. Effect of denture cleansers on metal ion release and surface roughness of denture base materials. Braz Dent J. 2012;23(4):387-93.

10. Webb BC, Thomas CJ, Whittle T. A 2-year study of Candidaassociated denture stomatitis treatment in aged care subjects. Gerodontology. 2005;22(3):168-76.

11. Felipucci DNB, Davi LR, Paranhos HFO, Bezzon OL, Silva RF, Pagnano VO. Effect of different cleansers on the surface of removable partial denture. Braz Dent J. 2011;22(5):392-7.

12. Geurtsen W. Bicompatibility of dental casting alloys. CROBM. 2002;13(1):71-84.

13. Videla HA, Herrera LK. Microbiologically influenced corrosion: looking to the future. Int Microbiol. 2005;8(3):169-80.

14. Koh I, Oshida Y, Andres CJ, Gregory RL. Effect of surface areas ratios and bacteria on electrochemical behavior of galvanically coupled titanium. Int J Prosthodont. 2008;21(5):433-6.

15. Correa CB, Pires JR, Fernandes-Filho RB, Sartori R, Vaz LG. Fatigue and Fluoride Corrosion on Streptococcus mutans adherence to titanium-based implant/component surfaces. J Prosthodont. 2009;18(5):382-7.

16. Keyf R, Güngör T. Comparison of effects of bleach and cleansing tablet on reflectance and surface changes of a dental alloy used for removable partial dentures. J Biomater Appl. 2003;18(1):514.

17. Paranhos HFO, Peracini A, Pisani MX, Oliveira VC, Souza RF, Silva-Lovato $\mathrm{CH}$. Color stability, surface roughness and flexural strength of an acrylic resin submitted to simulated overnight immersion in denture cleansers. Braz Dent J. 2013;24(2):152-6.

18. Espallargas N, Mischler S. Dry wear and tribocorrosion mechanisms of pulsed plasma nitrided Ni-Cr alloy. Wear. 2011;270(7-8):464-71.

19. Qiu J, Yu W-Q, Zhang FQ, Smales RJ, Zhang Y-L, Lu C-H. Corrosion behavior and surface analysis of a Co-Cr and two Ni-Cr dental alloys before and after simulated porcelain firing. Eur J Oral Sci. 2011;119(1):93-101.

20. Luo X, Li X, Sun Y, Dong H. Tribocorrosion behavior of S-phase surface engineered medical grade CoCr alloy. Wear. 2013;(1-2):1615-23.

21. Wataha JC. Biocompatibility of dental casting alloys: a review. J Prosthet Dent. 2000;83(2):223-34.

22. Meyer JM. Corrosion resistance of nickel-chromium dental casting alloys. Corros Sci. 1977;17(12):971-82.

23. Reclaru L, Meyer JM. Study of corrosion between a titanium implant and dental alloys. J Dent. 1994;22(3):159-68.

24. Saji VS, Choe HC. Electrochemical behaviour of $\mathrm{Co}-\mathrm{Cr}$ and $\mathrm{Ni}-\mathrm{Cr}$ dental cast alloys. Trans Nonferrous Met Soc China. 2009;19(4):785-90

25. Tuna SH, Pekmez NO, Keyf F, Canli F. The influence of the pure components of four different casting alloys on the electrochemical properties of the alloys. Dent Mater. 2009;25(9):1096-103.

26. Kedici SP, Ciksüt AA, Kilíçarslan MA, Bayramoglu G, Gökdemir $\mathrm{K}$. Corrosion behavior of dental metals and alloys in diferent media. J Oral Rehabil. 1998;25(10):800-8.

27. Vieira AC, Ribeiro AR, Rocha LA, Celis JP. Influence of $\mathrm{pH}$ and inhibitors on the tribocorrosion of titanium in artificial saliva. Wear. 2006;261(9):994-1001.

28. Abey S, Mathew MT, Lee DJ, Knoernschild KL, Wimmer MA, Sukotjo C. Electrochemical behavior of titanium in artificial saliva: influence of pH. J Oral Implantol. 2014;40(1):3-10.

29. Shiff N, Dalard F, Lissac M, Morgon L, Grosgogeat B. Corrosion resistance of three orthodontic brackets: a comparative study of three fluoride mouthwashes. Eur J Orthod. 2005;27(6):541-9.

30. Sartori R, Correa CB, Marcantonio Jr E, Vaz LGL. Influence of a fluoridated medium with different $\mathrm{pHs}$ on commercially pure titanium-based implants. J Prosthodont. 2009;18(2):130-4.

31. Toniollo MB, Galo R, Macedo AP, Rodrigues RCS, Ribeiro RF, Mattos MGC. Effect of fluoride sodium mouthwash solutions on cpTi: evaluation of physicochemical properties. Braz Dent J. 2012;23(5):496-501.

32. Al-Hiyasat AS, Bashabsheh OM, Darmani H. Elements released from dental casting alloys and their cytotoxic effects. Int $\mathrm{J}$ Prosthodont. 2002;15(5):473-8.

33. Upladhyay D, Panchal MA, Dubey RS, Srivastava VK. Corrosion of alloys used in dentistry: a review. Mater Sci Eng A. 2006;432(1-2):1-11.

34. Sarantopoulos DM, Beck KA, Holsen R, Berzins DW. Corrosion of $\mathrm{CoCr}$ and $\mathrm{NiCr}$ dental alloys alloyed with palladium. J Prosthet Dent. 2010;105(1):35-43.

35. Campanha NH, Pavarina AC, Jorge JH, Vergani CE, Machado AL, Giampaolo ET. The effect of long-term disinfection procedures on hardness property of resin denture teeth. Gerodontology. 2012;29(2):571-6.

36. Pisani MX, Macedo AP, Paranhos HFO, Silva CHL. Effect of experimental Ricinus communis solution for denture cleaning on the properties of acrylic resin teeth. Braz Dent J. 2012;23(1):1521.

37. Garcia RCMR, Souza JA Jr, Rached RN, Cury AADB. Effect of denture cleansers on the surface roughness and hardness of a microwave-cured acrylic resin and dental alloys. J Prosthodont. 2004;13(3):173-8. 